\title{
Fabrication of large-scale nanoporous nickel with a tunable pore size for energy storage
}

\author{
H-J. Qiu, ${ }^{a}$ J.L. Kang, ${ }^{a}$ P. Liu, ${ }^{a}$ A. Hirata, ${ }^{a}$ T. Fujita, ${ }^{a}$ M.W. Chen ${ }^{a}$ b, c* \\ ${ }^{a}$ WPI Advanced Institute for Materials Research, Tohoku University, Sendai 980-8577, Japan \\ ${ }^{b}$ State Key Laboratory of Metal Matrix Composites, School of Materials Science and Engineering, \\ Shanghai Jiao Tong University, Shanghai 200030, China \\ ${ }^{c}$ CREST, Japan Science and Technology Agency, Saitama 332-0012, Japan \\ *Email: mwchen@wpi-aimr.tohoku.ac.jp
}

\begin{abstract}
Nanoporous $\mathrm{Ni}$ with a tunable nanopore size and chemical compositions was fabricated by dealloying a $\mathrm{Ni}_{30} \mathrm{Mn}_{70}$ precursor alloy at various temperatures. The influence of electrochemical parameters on the formation of large-scale nanoporous Ni was systematically investigated. Different from the fabrication of nanoporous noble metals ( $\mathrm{Au}, \mathrm{Pt}$ and $\mathrm{Pd}$ ), the dealloying of $\mathrm{Ni}_{30} \mathrm{Mn}_{70}$ includes three kinetically competitive processes: dissolution of $\mathrm{Mn}$, interface diffusion of $\mathrm{Ni}$ and dissolution of Ni. The nanopore size and residual Mn can be tailored by controlling the dealloying time, temperature and applied potential. The as-dealloyed nanoporous $\mathrm{Ni}$ with a large internal surface area, excellent conductivity and naturally formed oxide surface can be directly used as a free-standing electrode for electrochemical supercapacitors with a high capacitance and excellent cycling stability.
\end{abstract}




\section{Introduction}

Dealloyed nanoporous metals are emerging as a new class of functional materials for both basic research and industrial applications. Owing to their prominent electrical conductivity, enhanced physicochemical activity and high surface area, nanoporous metals possess many unique properties for applications in catalysis, sensing, photonics, energy storage, and so on [1-9]. A common strategy to make nanoporous metals is based on the replication of porous inorganic and polymeric templates. For example, Ni foams with different porosities have been prepared by using porous templates $[10,11]$. The templating strategy can precisely control the size and morphology of the porous metals but is generally difficult to implement and time consuming. Recently, the dealloying approach has been receiving increased attention because it is capable of fabricating bulk nanoporous metals with bicontinuous open porosity by one-step chemical/electrochemical etching. The pore size, porosity and chemical composition of the dealloyed nanoporous metals can be tailored by controlling dealloying condition and precursor composition $[9,12]$. However, because dealloying is essentially a corrosion process, the resulting products are usually nanoporous noble metals, such as gold, platinum, palladium and silver etc., [8, 13-19] as a consequence of their high chemical stability. Driven by low-cost practical applications, developing economic nanoporous transition metals, such as copper and nickel, has been the recent topics of intense studies [20-22]. For nanoporous Ni (np-Ni), commercial Raney Ni by the alkali leaching of Al from NiAl alloy has been used as an industry catalyst for more than 80 years [23]. However, due to the multiple intermetallic phases in the precursor $\mathrm{Ni}-\mathrm{Al}$ alloy [24], the porous structure in Raney $\mathrm{Ni}$ is heterogeneous with a large variation in pore size and porosity. Moreover, brittle nature of the precursor Ni-Al alloy limits the Raney Ni only in the form of powders. The structure feature of Raney Ni is certainly inconsequential to the use as a catalyst that only requires a large effective surface area. It is apparently not adequate for applications where a large-scale homogeneous material is needed, for example, as a free-standing electrode for energy storage and conversion. To 
fabricate uniform bulk np-Ni by dealloying, the selection of precursor alloys is critical. As a general rules, an ideal precursor alloy is expected to be a homogeneous single phase to guarantee the formation of a uniform nanoporous structure and the dissolved elements have a large electrochemical potential difference from $\mathrm{Ni}$ for a wide dealloying potential window. To fabricate a large-scale bulk np-Ni for electrode applications, the precursor alloy is also required to have a good formability and can be easily fabricated into thin sheet by rolling or melt spinning. A single-phase $\mathrm{NiCu}$ alloy has been used as precursor to fabricate np-Ni by electrochemical dealloying $[25,26]$. Because $\mathrm{Cu}$ is chemically more stable than $\mathrm{Ni}$, the selective dissolution of $\mathrm{Cu}$ from the alloy is based on the passivation of Ni under a special electrochemical condition. Since the low diffusivity of the passivated $\mathrm{Ni}$, it is difficult to form a uniform nanoporous structure on large scale. Recently, it was reported that a uniform nanoporous structure can be achieved by using a ductile $\mathrm{Ni}_{30} \mathrm{Mn} 70$ alloy as the precursor [22]. From the Ni-Mn binary phase diagram, it can be seen that Ni30Mn70 falls into a single-phase region. More importantly, the standard reversible potential of $\mathrm{Mn}$ is $-1.135 \mathrm{~V}$ (vs. standard hydrogen electrode (SHE)), whereas $\mathrm{Ni}$ is $-0.250 \mathrm{~V}$ (vs. SHE). The $0.885 \mathrm{~V}$ gap between $\mathrm{Mn}$ and Ni provides a wide potential window to manipulate the dealloying process for selectively leaching Mn from the binary alloy in a controllable manner.

In this study we systematically investigate the formation and nanoporosity evolution of np-Ni by dealloying a bulk $\mathrm{Ni}_{30} \mathrm{Mn}_{70}$ precursor at various electrochemical conditions to develop a large-scale np-Ni with controllable structure and composition for the applications of energy storage. To demonstrate the potential applications of the economic and large scale nanoporous material, we show that the np-Ni with a naturally formed oxide surface can be directly used as a binder-free electrochemical supercapacitor electrode with high capacitive performances.

\section{Experimental}


$\mathrm{Ni}_{30} \mathrm{Mn}_{70}$ ingots were prepared by melting pure $\mathrm{Ni}$ and $\mathrm{Mn}(>99.9$ at.\%) using an Ar-protected arc melting furnace. After annealing at $900{ }^{\circ} \mathrm{C}$ for $24 \mathrm{hrs}$ for microstructure and composition homogenization, the ingots were cold-rolled to a thickness of $\sim 50 \mu \mathrm{m}$ at room temperature. Nanoporous Ni were prepared by chemical and electrochemical dealloying in various $\left(\mathrm{NH}_{4}\right)_{2} \mathrm{SO}_{4}$ aqueous solutions at different temperatures and applied potentials. After dealloying, the samples were rinsed thoroughly with water and ethanol.

The crystal structure of the precursor alloys and dealloyed samples were characterized by X-ray diffraction using a Rigaku RINTUltima X-ray diffractometer with $\mathrm{Cu} \mathrm{Ka}$ radiation. The microstructures of the dealloyed samples were characterized by transmission electron microscopy (TEM, JEOL JEM-2010F) and scanning electron microscopy (SEM, JEOL JSM-6700). Chemical analysis was performed by an energy-dispersive X-ray spectrometer (EDS, Oxford INCA x-sight). $\mathrm{N}_{2}$ adsorption/desorption experiment was conducted at 77K using a Quantachrome Autosorb-3B surface analyzer. Electrochemical dealloying and capacitance tests were carried out at room temperature using an electrochemical workstation (Iviumstat Technology) in a three-electrode cell with a Pt foil served as counter electrode and a saturated calomel electrode (SCE) as the reference electrode. The electrolytes used for chemical/electrochemical dealloying were $\left(\mathrm{NH}_{4}\right)_{2} \mathrm{SO}_{4}$ aqueous solutions with different concentrations. For capacitive performance measurements, $1 \mathrm{M} \mathrm{KOH}$ was chosen as the electrolyte. The nominal area of the samples immersed into the electrolyte for electrochemical tests was controlled to be $\sim 25 \mathrm{~mm}^{-2}$.

\section{Results and discussion}

\subsection{Structural characterization of the precursor $\mathrm{Ni}_{30} \mathrm{Mn}_{70}$ alloy}


The $\mathrm{Ni}_{30} \mathrm{Mn}_{70}$ alloy ingots have very good ductility at room temperature and can be cold-rolled to thin sheets with a thickness down to tens of micrometers. Fig. 1a and b are the optical images of cold-rolled $\mathrm{Ni}_{30} \mathrm{Mn}_{70}$ sheets with a thickness of $\sim 50 \mu \mathrm{m}$. The alloy sheets have a mirror finish surface and are very flexible and ductile for bending and plastic deformation. Fig. 1c is the EDS spectrum of the alloy sheets, from which only Ni and Mn bands can be identified. Quantitative analysis confirms that the Ni:Mn atomic ratio is $\sim 30: 70$, which is in excellent agreement with the nominal composition of the alloy. The X-ray diffraction (XRD) pattern of the cold-rolled $\mathrm{Ni}_{30} \mathrm{Mn}_{70}$ precursor, shown in inset of Fig. 1d, demonstrates that the sample is a single-phase alloy. All the diffraction peaks can be indexed as a face-centered cubic (fcc) phase with the main diffraction peaks of (111), (200), and (220). The microstructure of the cold-rolled alloy was characterized by SEM. As shown in Fig. 1d, the alloy has a uniform polycrystalline structure with elongated grains. The average width of the grains is $\sim 3-5 \mu \mathrm{m}$ and the length is $\sim 5-10 \mu \mathrm{m}$. Secondary phases and inclusions with different contrast cannot be found in the precursor alloy.

\subsection{Chemical dealloying}

\subsubsection{Effects of dealloying temperature and time}

According to the chemical properties of manganese, Mn-based alloys are unstable in acid solutions. Since Ni is also not stable in strong acid solutions, a weak acidic solution is appropriate for selectively dissolving $\mathrm{Mn}$ from the $\mathrm{Ni}_{30} \mathrm{Mn}_{70}$ alloy while $\mathrm{Ni}$ dissolution is insignificant and can be remained to form a nanoporous structure. With a $1 \mathrm{M}\left(\mathrm{NH}_{4}\right)_{2} \mathrm{SO}_{4}$ solution, it has been found that the dealloying is very slow at room temperature. It took $\sim 6 \mathrm{hrs}$ for the entire $50 \mu \mathrm{m}$-thick $\mathrm{Ni}_{30} \mathrm{Mn}_{70}$ precursor to turn into a nanoporous structure. The plane-view (Fig. 2a) and section-view (Fig. 2b and 2c) SEM images show that the nanopore size of the nanoporous $\mathrm{Ni}$ is $\sim 5-7 \mathrm{~nm}$ while the residual Mn is as high as $\sim 43$ at.\% (Fig. 2d). With the increase of dealloying time, the content of the 
residual Mn decreases gradually and finally reaches $\sim 23$ at.\% after 24 hrs (Fig. 2e). However, the ligament and pore sizes of the dealloyed np-Ni do not show obvious changes with the dealloying time (Fig. 2e). Brunauer-Emmett-Teller (BET) surface area analysis shows that np-Ni with a mean pore size of $\sim 6 \mathrm{~nm}$ has a high specific area of $\sim 61 \mathrm{~m}^{2} \mathrm{~g}^{-1}$, which are consistent well with the microstructural characterization.

There are two ways to expedite the selective etching: increasing dealloying temperatures for a high reaction rate and applying electric potentials to promote Mn dissolution. For the effect of applied potential, we will discuss in the next section. Since high temperatures can dramatically speed up chemical reactions, we increased the environmental temperatures of dealloying from room temperature to 50,70 and $90^{\circ} \mathrm{C}$. It was found that quick and smooth etching of Mn takes place at 50 ${ }^{\circ} \mathrm{C}$ as indicated by the quick bubbling on the alloy surface. After $\sim 1 \mathrm{hr}$, the bubbling stopped, suggesting that most $\mathrm{Mn}$ has been dissolved from the precursor alloy. Fig. 3a is the SEM micrograph of the $1 \mathrm{hr}$ dealloyed sample, which shows a uniform nanoporous structure. From the cross-sectional SEM image (Fig. 3b), it can be seen that the nanoporous structure distributes uniformly across the entire sample with the thickness of $50 \mu \mathrm{m}$, confirming that the dealloying has been completed within 1 hour by free etching at $50{ }^{\circ} \mathrm{C}$. When the dealloying time is extended, obvious growth of the nanoporous structure occurs. The average pore size, determined by a fast Fourier transform (FFT) method [27], gradually increases from $\sim 8.2 \mathrm{~nm}$ at $1 \mathrm{hr}, 10.2 \mathrm{~nm}$ at $3 \mathrm{hrs}$ to $12.8 \mathrm{~nm}$ at $5 \mathrm{hrs}$ (Fig. 4a). XRD patterns of the dealloyed samples also show significant structure changes during dealloying (Fig. 4b). After dealloying, the diffraction peaks of the samples shift to high angles, indicating the decrease of the lattice constant caused by the dissolution of Mn that has a larger atomic size than Ni. Compared to that of the precursor, the diffraction peaks of the dealloyed samples become much broader because of the formation of nano-sized metallic ligaments. The diffraction peaks become sharp and slightly shift to high angles with the growth of the nanoporous 
structure and the continuous dissolution of Mn. From the full width at half maximum (FWHM) measurements of the peak intensity, we can approximately estimate the characteristic size of $\sim 5.0$ $\mathrm{nm}$ for the 2-hr dealloyed sample and $\sim 8.7 \mathrm{~nm}$ for the 5-hr dealloyed one, which are slightly smaller than those of the FFT measurements. This deviation may be related to the size inconsistence between nanopores and Ni ligaments. In addition to the diffraction peaks from the fcc structure, an additional broad peak associated with a $\mathrm{Ni}$ oxide (located between $60^{\circ}$ and $65^{\circ}$ ) can also be observed. Quantitative composition measurements by EDS suggest that the residual Mn in the dealloyed samples depends on the dealloying time (Fig. 4c). In the $1 \mathrm{hr}$ dealloyed sample, there is $\sim 23$ at.\% residual Mn while the Mn concentration reduces to $\sim 6$ at.\% after 5 hrs. It is worth noting that when the dealloying time is longer than $5 \mathrm{hrs,} \mathrm{obvious} \mathrm{dissolution} \mathrm{of} \mathrm{Ni} \mathrm{takes} \mathrm{place,} \mathrm{leading} \mathrm{to}$ the crash of the nanoporous structure. Although the dealloyed samples become much more brittle compared to the precursor, micro-cracks and flaws cannot be found from the dealloyed nanoporous sheets. The dealloyed sheets still keep the original precursor shape and can be easily handled by a tweezer (inset in Fig. 4d). Therefore, large-scale np-Ni samples can be directly used as a bulk electrode in supercapactiors, batteries and fuel cells without a complex assembly process.

At $70{ }^{\circ} \mathrm{C}$, the dealloying rate further increases since more intense $\mathrm{H}_{2}$ bubbling can be formed within very short time. After dealloying for $1 \mathrm{hr}$, uniform and well-developed nanoporous structure can be obtained (Fig. 5a) and the residual $\mathrm{Mn}$ in the porous material is $\sim 8$ at.\%, much lower than that in the sample dealloyed at $50{ }^{\circ} \mathrm{C}$ for $1 \mathrm{hr}$. When extending the dealloying time to $1.5 \mathrm{hrs}$, it can be observed that the pore size increases more remarkably compared with the ligament size (Fig. 5b and Fig. 4a), indicating the partial dissolution of Ni. When the dealloying time is $\sim 3.5 \mathrm{hrs}$, the Ni dissolution leads to the serious damage of the nanoporous structure (Fig. 5c). Therefore, at the dealloying temperature of $70{ }^{\circ} \mathrm{C}$, a short dealloying time of $\sim 1$ to $2 \mathrm{hrs}$ is appropriate for producing np-Ni with a uniform nanoporous structure. 
When the dealloying temperature is increased to $90{ }^{\circ} \mathrm{C}$, the selective etching reaction becomes much faster with more intense bubbling. After only $30 \mathrm{~min}$, the nanoporous structure is already damaged by the dissolution of $\mathrm{Ni}$ and the residual $\mathrm{Mn}$ in the sample is just $\sim 6$ at.\%. Apparently, the dealloying temperature of $90^{\circ} \mathrm{C}$ is too high to get uniform np-Ni.

Since the Mn dissolution is much faster than that of the surface diffusion of $\mathrm{Ni}$ in the electrolyte, the nanopore formation can be assumed to be controlled by a slow surface diffusion of Ni. The diffusivity $\left(D_{s}\right)$ of metal atoms can be estimated by the equation [28]:

$$
D_{s}=d(t)^{4} k T / 32 \gamma t a^{4}
$$

where $k$ is Boltzmann constant $\left(1.3806 \times 10^{-23} \mathrm{~J} \mathrm{~K}^{-1}\right), t$ is the dealloying time, $T$ is the dealloying temperature, $\gamma$ is surface energy, and $a$ represents the lattice parameter. Adopting $\gamma_{\mathrm{Ni}}=2.00 \mathrm{~J} \mathrm{~m}^{-2}$ [29] and $a_{\mathrm{Ni}}=0.35238 \mathrm{~nm}$, the calculated $D_{s}$ are $2.8 \times 10^{-23}, 6.3 \times 10^{-21}$ and $1.6 \times 10^{-20}$ at $25^{\circ} \mathrm{C}, 50^{\circ} \mathrm{C}$ and $70{ }^{\circ} \mathrm{C}$, respectively. Therefore, increasing the dealloying temperature for just $25{ }^{\circ} \mathrm{C}$ can significantly improves the surface diffusivity of $\mathrm{Ni}$ to over one order of magnitude for the fast formation of porous structure. Since high temperature also promotes Ni dissolution in the weak acid and leads to the destruction of nanoporous structure, the best dealloying temperature for np-Ni appears to be 50 to $70{ }^{\circ} \mathrm{C}$ at which the selective etching of $\mathrm{Ni}_{30} \mathrm{Mn}_{70}$ takes place at a controllable time scale with insignificant Ni dissolution.

The microstructure of np-Ni fabricated by $2 \mathrm{~h}$ dealloying at $50{ }^{\circ} \mathrm{C}$ was characterized by highresolution transmission electron microscopy (HRTEM) and scanning transmission electron microscopy (STEM). Fig. 6a is a bright-field TEM micrograph, showing a nanoporous structure with dark-contrast ligaments and bright nanopores. The pore size is $\sim 5-8 \mathrm{~nm}$, in the good agreement with the SEM observation. However, different from the nanoporous noble metals (such as $\mathrm{Au}, \mathrm{Pt}$ and Pd), the ligament surface of np-Ni is very rough (Fig. 6b) because of surface oxidation of the highly active nanoporous metal. The Ni surface oxides should be formed naturally when np-Ni is 
exposed to air. The formation of the Ni surface oxides was further confirmed by selected-area electron diffraction (SAED, Fig. 6c). In addition to the fcc Ni, diffraction rings from $\mathrm{NiO}(200)$ and (210) can also be observed from the SAED pattern. Fig. 6d shows the high-angle annular dark field (HAADF) STEM image in which the contrast mainly comes from the mass difference between Ni ligaments and nanopores. The bicontinuous structure with spinodal morphology can be well recognized. The average ligament size of $\sim 8 \mathrm{~nm}$ is consistent with previous SEM measurement. A representative ligament-pore structure and the corresponding element mappings show that $O$ from metal oxides mainly distributes on the ligament surface, forming a core-shell-like structure. The distribution of the residual $\mathrm{Mn}$ is not uniform and $\mathrm{Mn}$ rich regions can be observed from the $\mathrm{Mn}$ mapping. However, the Mn heterogeneity does not couple with that of $\mathrm{O}$, suggesting the formation of $\mathrm{Mn}$ rich domains in the dealloyed sample, similar to the case of residual Ag in dealloyed nanoporous gold [30].

\subsubsection{Effect of electrolyte concentration}

Since electrolyte is an important factor controlling the dealloying rate and nanopore formation, we investigated the effect of $\left(\mathrm{NH}_{4}\right)_{2} \mathrm{SO}_{4}$ concentrations of the electrolytes on the dealloying of $\mathrm{Ni}_{30} \mathrm{Mn}_{70}$ at the optimal temperature of $50{ }^{\circ} \mathrm{C}$. Using a dilute $0.2 \mathrm{M}\left(\mathrm{NH}_{4}\right)_{2} \mathrm{SO}_{4}$ solution, the dealloying rate of $\mathrm{Ni}_{30} \mathrm{Mn}_{70}$ becomes much slower, compared to the $1 \mathrm{M}\left(\mathrm{NH}_{4}\right)_{2} \mathrm{SO}_{4}$ solution. After dealloying for $3 \mathrm{~h}$, uniform $\mathrm{np}-\mathrm{Ni}$ with fine ligaments/pores of $\sim 5.6 \pm 0.2 \mathrm{~nm}$ and residual $\mathrm{Mn}$ of $\sim 7.6$ at.\% was obtained (Fig. 7). The ligament/pore size is obviously smaller than that acquired by 3 h dealloying in $1.0 \mathrm{M}\left(\mathrm{NH}_{4}\right)_{2} \mathrm{SO}_{4}$ solution $(\sim 10.2 \pm 0.4 \mathrm{~nm})$. When $2.0 \mathrm{M}\left(\mathrm{NH}_{4}\right)_{2} \mathrm{SO}_{4}$ was used, the obtained $\mathrm{np}-\mathrm{Ni}$ showed negligible structure change compared with that obtained in $1.0 \mathrm{M}$ $\left(\mathrm{NH}_{4}\right)_{2} \mathrm{SO}_{4}$ solution. When a high concentration $\left(\mathrm{NH}_{4}\right)_{2} \mathrm{SO}_{4}$ solution of $4.0 \mathrm{M}\left(\mathrm{NH}_{4}\right)_{2} \mathrm{SO}_{4}$ was used, the dissolution of both $\mathrm{Mn}$ and Ni becomes very quick, which is not suitable for the fabrication of np-Ni. 
It has been reported that coarsened nanoporous structure can be achieved when the dealloying solution contains $\mathrm{Cl}^{-}$ions. It was suggested that $\mathrm{Cl}^{-}$enhances the surface diffusivity of $\mathrm{Au}$ and $\mathrm{Pd}$ atoms during dealloying Al-based alloys [31-33]. In the present study, however, we did not observe obvious microstructure coarsening when a $2.0 \mathrm{M} \mathrm{NH} 4 \mathrm{Cl}$ solution was used to dealloy the $\mathrm{Ni}_{30} \mathrm{Mn}_{70}$ alloy, suggesting the coarsening effect in Al-based precursors may be due to the enhanced corrosion of $\mathrm{Al}$ by the $\mathrm{Cl}^{-}$anions [34].

\subsection{Electrochemical dealloying}

It is known that electric potentials can promote selective corrosion for rapid formation of nanoporous structure. Because of the low standard reversible potential of $\mathrm{Mn}$, in principle, electrochemically dealloying $\mathrm{Mn}$ from the $\mathrm{Ni} 30 \mathrm{Mn} 70$ alloy can be carried out in neutral solutions, such as $\mathrm{NaCl}$ aqueous solutions, and an acidic environment may be not necessary. However, during the electrochemical dealloying, $\mathrm{Mn}^{2+}$ ions are formed $\left(\mathrm{Mn}-2 \mathrm{e}=\mathrm{Mn}^{2+}\right)$ at the anodic electrode while $\mathrm{H}_{2} \mathrm{O}$ are reduced into $\mathrm{H}_{2}$ and $\mathrm{OH}^{-}$at the cathodic electrode $\left(2 \mathrm{H}_{2} \mathrm{O}+2 \mathrm{e}=\mathrm{H}_{2}+2 \mathrm{OH}^{-}\right) . \mathrm{Mn}^{2+}$ can react with $\mathrm{OH}^{-}$to form $\mathrm{Mn}(\mathrm{OH})_{2}$ precipitates on the precursor alloy surface to prevent the proceeding of dealloying. Since the $\mathrm{Mn}(\mathrm{OH})_{2}$ precipitates are soluble in an acidic or $\mathrm{NH}^{4+}$ containing solution, an weak acid solution, such as $\left(\mathrm{NH}_{4}\right)_{2} \mathrm{SO}_{4}$, is still required for the electrochemical dealloying of the $\mathrm{Ni}_{30} \mathrm{Mn}_{70}$ alloy.

Fig. $8 \mathrm{a}$ is the anodic polarization curves of the $\mathrm{Ni}_{30} \mathrm{Mn}_{70}$ alloy in electrolytes with different $\left(\mathrm{NH}_{4}\right)_{2} \mathrm{SO}_{4}$ concentrations. It can be seen that the selective dissolution of $\mathrm{Mn}$ can be carried out at a wide potential range. The currents from etching of Mn increase with both the applied potentials and the $\left(\mathrm{NH}_{4}\right)_{2} \mathrm{SO}_{4}$ concentrations. For comparison, Fig. $8 \mathrm{~b}$ shows the anodic polarization curves of pure Ni. The obvious dissolution of $\mathrm{Ni}$ starts from the potential higher than $-0.3 \mathrm{~V}$. Thus, three potentials (i.e., $-0.75 \mathrm{~V},-0.6 \mathrm{~V}$, and $-0.45 \mathrm{~V}$ ) were chosen for electrochemically dealloying 
$\mathrm{Ni}_{30} \mathrm{Mn}_{70}$ in the $1 \mathrm{M}\left(\mathrm{NH}_{4}\right)_{2} \mathrm{SO}_{4}$ solution. The current-time curves of dealloying at different potentials were shown in Fig. $8 \mathrm{c}$. At the initial stage, $\mathrm{Mn}$ dissolution (forming $\mathrm{Mn}^{2+}$ ) is very fast because of the high content of $\mathrm{Mn}$ in the precursor. Upon Mn dissolving, exposed Ni atoms at the electrode/electrolyte interface diffuse and assemble to form a rough nanoporous interface with the electrolyte. This process exposes more fresh surfaces thus accelerates the dealloying reaction and results in a gradual rise in the current density. With the dissolution of the Mn atoms, the dealloying reaction progressively slows down due to the depletion of $\mathrm{Mn}$ in the precursor and thus the current decreases with time until the finish of the dealloying process. The higher the applied potential, the higher the dealloying current is and the less the time is needed for the selective dissolution of Mn. The SEM micrographs of np-Ni obtained at different potentials were shown in Fig. 9. Nanoporous $\mathrm{Ni}$ obtained at a higher dealloying potential has a remarkably coarsened ligament-pore structure compared with that at a lower potential although it takes shorter dealloying time at higher applied potentials. Based on the surface diffusion controlled coarsening mechanism (Eq. 1), the $D_{s}$ of $\mathrm{Ni}$ atoms at each dealloying potential can be approximately estimated to be $1.0 \times 10^{-21}$ (at $-0.75 \mathrm{~V}$ ), $1.8 \times 10^{-21}(-0.60 \mathrm{~V})$, and $4.7 \times 10^{-21} \mathrm{~m}^{2} \mathrm{~s}^{-1}(-0.45 \mathrm{~V})$. Thus, a higher dealloying potential can give rise

to a faster surface diffusivity of $\mathrm{Ni}$, which is similar to the potential-enhanced $\mathrm{Au}$ diffusivity reported before [35]. Nanoporous Ni can also been obtained at a constant dealloying current. The higher the dealloying current, the higher the potential is required (Fig. 8d).

\subsection{Electrochemical capacitance of nanoporous $\mathrm{Ni}$}

Since the as-prepared np-Ni naturally forms oxide covered internal surface when exposed to air and water (Fig. 6e), the core-shell-like NiO@np-Ni is expected to have a wide range of applications without further sample treatment because of nanostructured Ni oxides are important functional materials and np-Ni substrate proves a large effective surface area and high conductivity. In this study we demonstrated that this new material can be directly used as binder-free electrodes for 
electrochemical supercapacitors. Fig. 10a shows the typical CV curves of np-Ni (dealloyed at -0.6 $\mathrm{V}$ for $1 \mathrm{hr}$ ) at various sweep rates ranging from 2.5 to $20 \mathrm{mV} \mathrm{s}^{-1}$. The shape of the $\mathrm{CV}$ curves reveals the pseudocapacitive characteristics with a pair of redox peaks in the potential range from 0 to $0.5 \mathrm{~V}$ for all sweep rates, corresponding to the Faradaic redox reactions of NiO. At a low scan rate of $2.5 \mathrm{mV} \mathrm{s}^{-1}$, the reaction peaks locate at $\sim 0.19$ and $0.34 \mathrm{~V}$. When the scan rate increases to 20 $\mathrm{mV} \mathrm{s}^{-1}$, the positions of the cathodic and anodic peaks shift to 0.08 and $0.45 \mathrm{~V}$, respectively. Electrochemical impedance measurement (Fig. 10b) shows that the nanoporous electrode exhibits a small semicircle in the high frequency region, indicating the low charge-transfer resistance of the system. In the charge/discharge curves (Fig. 10c), there are voltage plateaus at around 0.25-0.20 V, consistent with previous report [36]. The areal specific capacitance is calculated by the formula [37],

$$
C=I \Delta t / S \Delta V
$$

where $I$ is the current, $\Delta t$ is the discharge time, $\Delta V$ is the voltage range and $S$ is the nominal area of the free-standing electrode. The calculated specific areal capacitance as the function of the discharge current density is plotted in Fig. 10d. The areal capacitance is $\sim 1.4-1.3 \mathrm{~F} \mathrm{~cm}^{-2}$ measured at the discharge current density from 1 to $20 \mathrm{~mA} \mathrm{~cm}$, better or at least comparable with the previously reported values for such free-standing pseudocapacitive electrodes, such as $\mathrm{Co}_{3} \mathrm{O}_{4} / \mathrm{MnO}_{2}$ nanowires/nanosheet structured electrode $\left(\sim 0.56 \mathrm{~F} \mathrm{~cm}^{-2}\right.$ at $\left.11.24 \mathrm{~mA} \mathrm{~cm}{ }^{-2}\right)$ [37], $\mathrm{Co}_{3} \mathrm{O}_{4}-\mathrm{NiO}$ coreshell nanowire electrode $\left(1.35 \mathrm{~F} \mathrm{~cm}^{-2}\right.$ at $\left.6 \mathrm{~mA} \mathrm{~cm}^{-2}\right)$ [38], $\mathrm{MnO}_{2}-\mathrm{NiO}$ core-shell nanoflake electrode $\left(0.35 \mathrm{~F} \mathrm{~cm}^{-2}\right.$ at $\left.9.5 \mathrm{~mA} \mathrm{~cm}^{-2}\right)$ [39], etc. More recently, a much higher areal capacitance of $3.12 \mathrm{~F} \mathrm{~cm}^{-}$ ${ }^{2}$ at a discharge current density of $1.11 \mathrm{~mA} \mathrm{~cm}^{-2}$ was reported from a $\mathrm{NiCo}_{2} \mathrm{O}_{4}$ nanoneedle/Ni foam electrode [40]. However, the capacitance decreases quickly from 3.12 to $0.59 \mathrm{~F} \mathrm{~cm}^{-2}$ when the current density increases from 1.11 to $22.24 \mathrm{~mA} \mathrm{~cm}^{-2}$. In comparison, the present np-Ni/NiO electrode is much more stable especially at higher current density, which is believed to be associated with the very thin oxide film on the Ni ligament surface. 
The cycling stability of the np-Ni electrode is evaluated by the repeated charging/discharging at a constant current density of $16 \mathrm{~mA} \mathrm{~cm}^{-2}$ (Fig. 10f). It is interesting to note that the areal capacitance gradually increased to $\sim 1.5 \mathrm{~F} \mathrm{~cm}^{-2}$ at the $\sim 2000$ th cycle. After 2000 cycles, the capacitance decreases slightly and then becomes nearly constant. The capacitance after 3000 cycles $\left(1.4 \mathrm{~F} \mathrm{~cm}^{-2}\right.$, current density: $16 \mathrm{~mA} \mathrm{~cm}{ }^{-2}$ ) is still superior, compared with the free-standing $\mathrm{NiCo}_{2} \mathrm{O}_{4}$ nanoneedle electrode after 2000 cycles ( $\sim 0.9 \mathrm{~F} \mathrm{~cm}^{-2}$, current density: $\left.5.56 \mathrm{~mA} \mathrm{~cm}^{-2}\right)$. After charging/discharging for 3000 cycles, the nanoporous morphology and ligament/pore size of the nanoporous composite can be well retained without remarkable change. To understand the anomalous cyclic stability of the electrode, the specific area capacitance of the 2000-cycled nanoporous composite electrode was investigated at different charge/discharge currents (Fig. 10d and e). It can be found that the area capacitance increases to $1.72-1.46 \mathrm{~F} \mathrm{~cm}^{-2}$ at the current density from 1 to $20 \mathrm{~mA} \mathrm{~cm} \mathrm{~cm}^{-2}$. The increment in the capacitance appears to be caused by the increased $\mathrm{NiO}$ coverage on the $\mathrm{Ni}$ ligament surface. At the current density of $1 \mathrm{~mA} \mathrm{~cm}^{-2}$, the calculated volume and mass (whole electrode mass) specific capacitance is $\sim 344 \mathrm{~F} \mathrm{~cm}^{-3}$ and $\sim 95 \mathrm{~F} \mathrm{~g} \mathrm{~g}^{-1}$, respectively, which is mainly because of a very small amount of $\mathrm{NiO}$ (surface oxide, smaller than $5 \%$ in weight) directly contributes to the capacitance.

The excellent electrochemical performances of the dealloyed $\mathrm{np}-\mathrm{Ni}$ are related to the following structural features. First, the small ligaments/pore size gives rise to a high effective surface area, which undoubtedly contributes to the high capacitance. Second, the well-defined bicontinuous open porosity makes the electrolyte easily access the nanopore channels for sufficient redox reactions, which can obviously enhance the electrochemical kinetics compared with conventional electrodes. Third, the direct growth of the NiO film on a conductive interconnected ligament surface can ensure intimately contact, and more importantly, facilitate the electron transfer from $\mathrm{NiO}$ to the metallic $\mathrm{Ni}$ ligaments for low internal resistance and electrochemical impedance [7]. 


\section{Conclusions}

In summary, a large scale np-Ni with uniform and tunable porosity has been successfully developed through one-step chemical/electrochemical dealloying of a precursor $\mathrm{Ni}_{30} \mathrm{Mn} 70$ alloy. The $\mathrm{Ni}{ }_{30} \mathrm{Mn} 70$ alloy can be chemically dealloyed at room temperature by weak acidic solutions. However, the dealloying process is very slow and a large amount of Mn remains in the dealloyed nanoporous structure. Increasing dealloying temperature can significantly enhance the surface diffusivity of $\mathrm{Ni}$ adatoms and dissolution rate of $\mathrm{Mn}$ and hence promotes the formation of np-Ni. However, as the side effect, high dealloying temperatures also leads to the dissolution of $\mathrm{Ni}$ and results in the damage of nanoporous structure. An intermediate temperature between 50 and $70^{\circ} \mathrm{C}$ is appropriate for fabricating $\mathrm{np}-\mathrm{Ni}$ at a controllable time scale without significant $\mathrm{Ni}$ dissolution. Applied potentials can also enhance the dissolution of $\mathrm{Mn}$ and interface diffusion of $\mathrm{Ni}$ for the rapid formation of np-Ni. However, similar to the temperature effect, high potentials lead to the dissolution of $\mathrm{Ni}$ and the crash of nanoporous structure. The suitable potential for dealloying the $\mathrm{Ni}_{30} \mathrm{Mn}_{70}$ precursor should be below $-0.45 \mathrm{~V}$ in a weak acidic solution to prevent the dissolution of Ni. The dealloyed np-Ni possesses high chemical activity and naturally oxidized surface when exposed to air and water. The as-dealloyed sample with a thin oxide skin and highly conductive metal cores can be directly used as a free-standing electrode for supercapacitors. Remarkably, the nanoporous electrode exhibits excellent capacitive performances with very high areal capacitance and outstanding cycling stability compared to other free-standing electrodes. Such nanoporous electrode obtained by dealloying is scalable and might offer great promise for fabrication of highperformance energy storage devices.

\section{Acknowledgements}


This work was sponsored by JST-CREST "Phase Interface Science for Highly Efficient Energy Utilization"; JST-PRESTO "New Materials Science and Element Strategy"; "World Premier International (WPI) Research Center Initiative for Atoms, Molecules and Materials”, MEXT, Japan; and Strategic Information and Communications R\&D Promotion Programme (SCOPE). H.J.Q. is

supported by the Japan Society for the Promotion of Science (JSPS) postdoctoral fellowship program (P12054).

\section{References}

[1] J. Erlebacher, M.J. Aziz, A. Karma, N. Dimitrov, K. Sieradzki, Nature 410 (2001) 450.

[2] J. Biener, A. Wittstock, L.A. Zepeda-Ruiz, M.M. Biener, V. Zielasek, D. Kramer, R.N. Viswanath, J. Weissmuller, M. Baumer, A.V. Hamza, Nat. Mater. 8 (2009) 47.

[3] H.J. Jin, J. Weissmuller, Science 332 (2011) 1179.

[4] J. Snyder, T. Fujita, M.W. Chen, J. Erlebacher, Nat. Mater. 9 (2010) 904.

[5] A. Wittstock, V. Zielasek, J. Biener, C.M. Friend, M. Baumer, Science 327 (2010) 319.

[6] T. Fujita, P.F. Guan, K. McKenna, X.Y. Lang, A. Hirata, L. Zhang, T. Tokunaga, S. Arai, Y. Yamamoto, N. Tanaka, Y. Ishikawa, N. Asao, Y. Yamamoto, J. Erlebacher, M.W. Chen, Nat. Mater. 11 (2012) 775.

[7] X.Y. Lang, A. Hirata, T. Fujita, M.W. Chen, Nat. Nanotechnol. 6 (2011) 232.

[8] Y. Ding, M.W. Chen, Mrs Bull 34 (2009) 569.

[9] L.H. Qian, X.Q. Yan, T. Fujita, A. Inoue, M.W. Chen, Appl. Phys. Lett. 90, 153120 (2007).

[10] I. Vukovic, S. Punzhin, Z. Vukovic, P. Onck, J.T.M. De Hosson, G. ten Brinke, K. Loos, ACS Nano 5 (2011) 6339.

[11] X. Zhang, K.N. Tu, J. Am. Chem. Soc. 128 (2006) 15036.

[12] J. Weissmuller, R.C. Newman, H.J. Jin, A.M. Hodge, J.W. Kysar, Mrs Bull 34 (2009) 577.

[13] Y. Ding, Y.J. Kim, J. Erlebacher, Adv. Mater. 16 (2004) 1897.

[14] L.Y. Chen, H. Guo, T. Fujita, A. Hirata, W. Zhang, A. Inoue, M.W. Chen, Adv. Funct. Mater. 21 (2011) 4364.

[15] J.I. Shui, C. Chen, J.C.M. Li, Adv. Funct. Mater. 21 (2011) 3357. 
[16] L.F. Liu, E. Pippel, R. Scholz, U. Gosele, Nano Lett. 9 (2009) 4352.

[17] R. Morrish, A.J. Muscat, Chem. Mater. 21 (2009) 3865.

[18] J.F. Huang, I.W. Sun, Adv. Funct. Mater. 15 (2005) 989.

[19] F. Jia, C. Yu, Z. Ai, L. Zhang, Chem. Mater. 19 (2007) 3648.

[20] L.Y. Chen, J.S. Yu, T. Fujita, M.W. Chen, Adv. Funct. Mater. 19 (2009) 1221.

[21] J.R. Hayes, A.M. Hodge, J. Biener, A.V. Hamza, K. Sieradzki, J. Mater. Res. 21 (2006) 2611.

[22] M. Hakamada, M. Mabuchi, J. Alloy. Compd. 485 (2009) 583.

[23] M. Raney, U.S. Patent 628 (1927) 190.

[24] Z. Qi, Z.H. Zhang, H.L. Jia, Y.J. Qu, G.D. Liu, X.F. Bian, J. Alloy Compd. 472 (2009) 71.

[25] L. Sun, C.L. Chien, P.C. Searson, Chem. Mater. 16 (2004) 3125.

[26] J.K. Chang, S.H. Hsu, I.W. Sun, W.T. Tsai, J. Phys. Chem. C 112 (2008) 1371.

[27] T. Fujita, M.W. Chen, Jpn. J. Appl. Phys. 47 (2008) 1161.

[28] G. Andreasen, M. Nazzarro, J. Ramirez, R.C. Salvarezza, A.J. Arvia, J. Electrochem. Soc. 143 (1996) 466.

[29] F.B. Swinkels, M.F. Ashby, Acta Metall. 29 (1981) 259.

[30] L. Zhang, L. Chen, H. Liu, Y. Hou, A. Hirata, T. Fujita, M. Chen, J. Phys. Chem. C 115 (2011) 19583.

[31] Z. Zhang, Y. Wang, Z. Qi, W. Zhang, J. Qin, J. Frenzel, J. Phys. Chem. C 113 (2009) 12629.

[32] R.C. Newman, K. Sieradzki, Science 263 (1994) 1708.

[33] M. Hakamada, M. Mabuchi, Nano Lett. 6 (2006) 882.

[34] S.S.A. Rehim, H.H. Hassan, M.A. Amin, Appl. Surf. Sci. 187 (2002) 279.

[35] J.M. Dona, J. Gonzalez-Velasco, J. Phys. Chem. 97 (1993) 4714.

[36] J.-H. Kim, K. Zhu, Y. Yan, C.L. Perkins, A.J. Frank, Nano Lett. 10 (2010) 4099.

[37] J.P. Liu, J. Jiang, C.W. Cheng, H.X. Li, J.X. Zhang, H. Gong, H.J. Fan, Adv. Mater. 23 (2011) 2076.

[38] X. Xia, J. Tu, Y. Zhang, X. Wang, C. Gu, X.-b. Zhao, H.J. Fan, ACS Nano 6 (2012) 5531.

[39] J.P. Liu, J. Jiang, M. Bosman, H.J. Fan, J. Mater. Chem. 22 (2012) 2419.

[40] G.Q. Zhang, H. Bin Wu, H.E. Hoster, M.B. Chan-Park, X.W. Lou, Energ. Environ. Sci. 5 (2012) 9453. 


\section{Figure captions:}

Fig. 1 (a) Photos of cold-rolled Ni30Mn70 alloy sheet with a thickness of $50 \mu \mathrm{m}$; (b) flexibility of the

Ni30Mn70; (c) EDS spectrum of the cold-rolled precursor; (d) SEM image of the Ni30Mn70 alloy and its XRD pattern (inset).

Fig. 2 SEM micrographs of np-Ni dealloyed in $1.0 \mathrm{M}\left(\mathrm{NH}_{4}\right)_{2} \mathrm{SO}_{4}$ at room temperature for 6 hrs. (a) Plane-view image; (b) Zoom-out cross-sectional SEM image; (c) the enlarged image taken from the central part of the sample (marked by the black rectangle in (b)). The nanoporous structure in the region demonstrates that the entire sample is dealloyed. (d) EDS pattern taken from this sample. (e) The variation of ligament size and residual Mn concentration with dealloying time.

Fig. 3 SEM images of np-Ni obtained by chemical dealloying in $1.0 \mathrm{M}\left(\mathrm{NH}_{4}\right)_{2} \mathrm{SO}_{4}$ for $1 \mathrm{~h}$ (a: plane view, and b: section view), $2 \mathrm{~h}(\mathrm{c})$ and $3 \mathrm{~h}(\mathrm{~d})$ at $50{ }^{\circ} \mathrm{C}$. Scale bar: $100 \mathrm{~nm}$.

Fig. 4 Microstructure and composition variation of np-Ni dealloyed in in $1.0 \mathrm{M}\left(\mathrm{NH}_{4}\right)_{2} \mathrm{SO}_{4}$. (a) Dependence of ligament size of np-Ni with dealloying time and temperature. (b) XRD patterns of the samples with different dealloying time at $50{ }^{\circ} \mathrm{C}$. (c) Dependence of the residual $\mathrm{Mn}$ concentration on dealloying time at $50{ }^{\circ} \mathrm{C}$; (d) EDS spectrum of np-Ni obtained by $2 \mathrm{~h}$ dealloying at $50^{\circ} \mathrm{C}$. The inset shows the optical image of a bulk np-Ni sample.

Fig. $5 \mathrm{SEM}$ images of np-Ni obtained by $70{ }^{\circ} \mathrm{C}$ chemical dealloying in $1.0 \mathrm{M}\left(\mathrm{NH}_{4}\right)_{2} \mathrm{SO}_{4}$ for (a) $1 \mathrm{~h}$, (b) $1.5 \mathrm{~h}$, and (c) $3.5 \mathrm{~h}$. Scale bar: $100 \mathrm{~nm}$.

Fig. 6 Microstructure of np-Ni obtained by $2 \mathrm{~h}$ dealloying in $1.0 \mathrm{M}\left(\mathrm{NH}_{4}\right)_{2} \mathrm{SO}_{4}$ at $50{ }^{\circ} \mathrm{C}$. (a) TEM micrograph; (b) HRTEM image; (c) SAED pattern; (d) dark-field STEM image; and (e) the element mappings. 
Fig. $7 \mathrm{SEM}$ images of np-Ni prepared by chemical dealloying in $0.2 \mathrm{M}\left(\mathrm{NH}_{4}\right)_{2} \mathrm{SO}_{4}$ for $3 \mathrm{~h}$ at $50{ }^{\circ} \mathrm{C}$. (a) low magnification image; and (b) high magnification.

Fig. 8 (a) Anodic polarization curves of $\mathrm{Ni}_{3} 0 \mathrm{Mn}_{70}$ alloy in $\left(\mathrm{NH}_{4}\right)_{2} \mathrm{SO}_{4}$ solutions with different concentrations. As reference, the anodic polarization curves of pure $\mathrm{Ni}$ in the same electrolytes are shown in (b). (c) Current-time curves at different potentials; and (d) potential-time curves at different applied currents during the dealloying process at room temperature.

Fig. 9 SEM images of np-Ni obtained by room-temperature electrochemical dealloying in $1.0 \mathrm{M}$ $\left(\mathrm{NH}_{4}\right)_{2} \mathrm{SO}_{4}$ at different potentials: (a) $-0.75 \mathrm{~V}$, (b) $-0.60 \mathrm{~V}$, and (c) $-0.45 \mathrm{~V}$.

Fig. 10 (a) CV curves of np-Ni at different scan rates. (b) Nyquist plot of the nanoporous structure tested from $100 \mathrm{kHz}$ to $0.1 \mathrm{~Hz}$ with the amplitude of $50 \mathrm{mV}$. (c) and (d) Charge-discharge curves and the area specific capacitance of $\mathrm{np}-\mathrm{Ni}$ as a function of current density. (e) Charge-discharge curves of np-Ni after 2000 charge/discharge cycles. (f) The area specific capacitance as a function of cycle number at a constant current density of $16 \mathrm{~mA} \mathrm{~cm}{ }^{-2}$. The electrolyte is $1 \mathrm{M} \mathrm{KOH}$ aqueous solution. 
Fig. 1
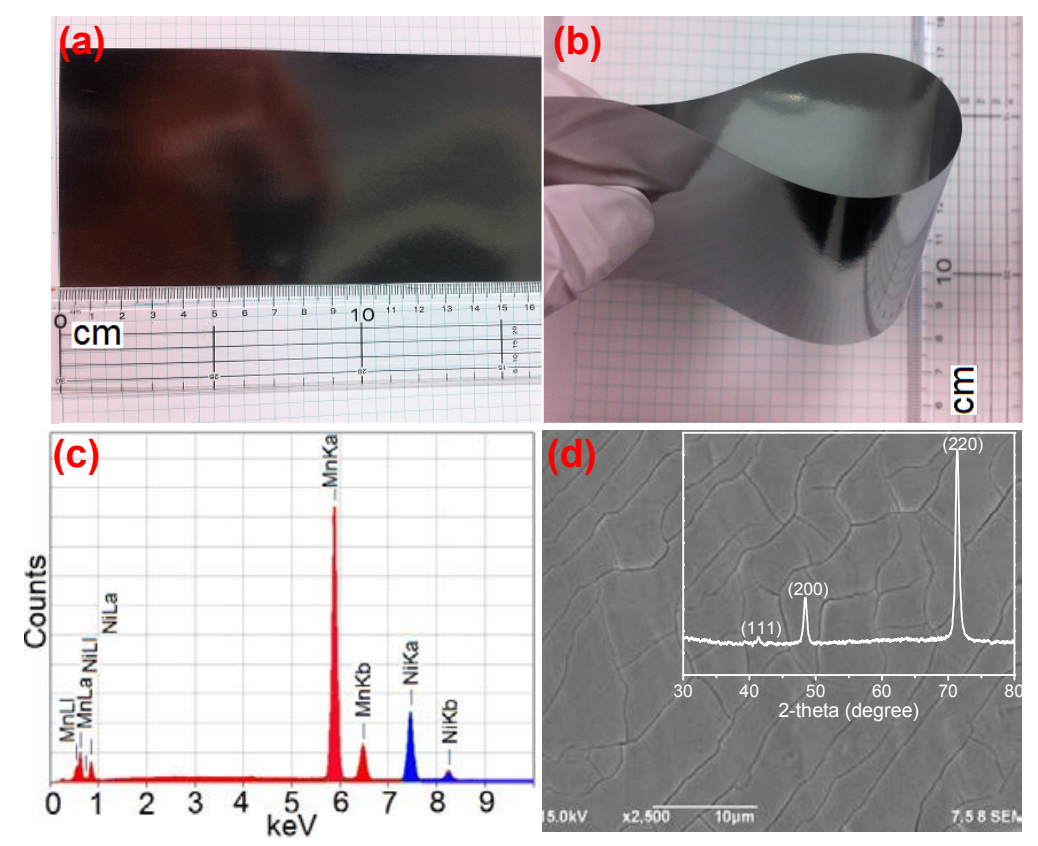
Fig. 2
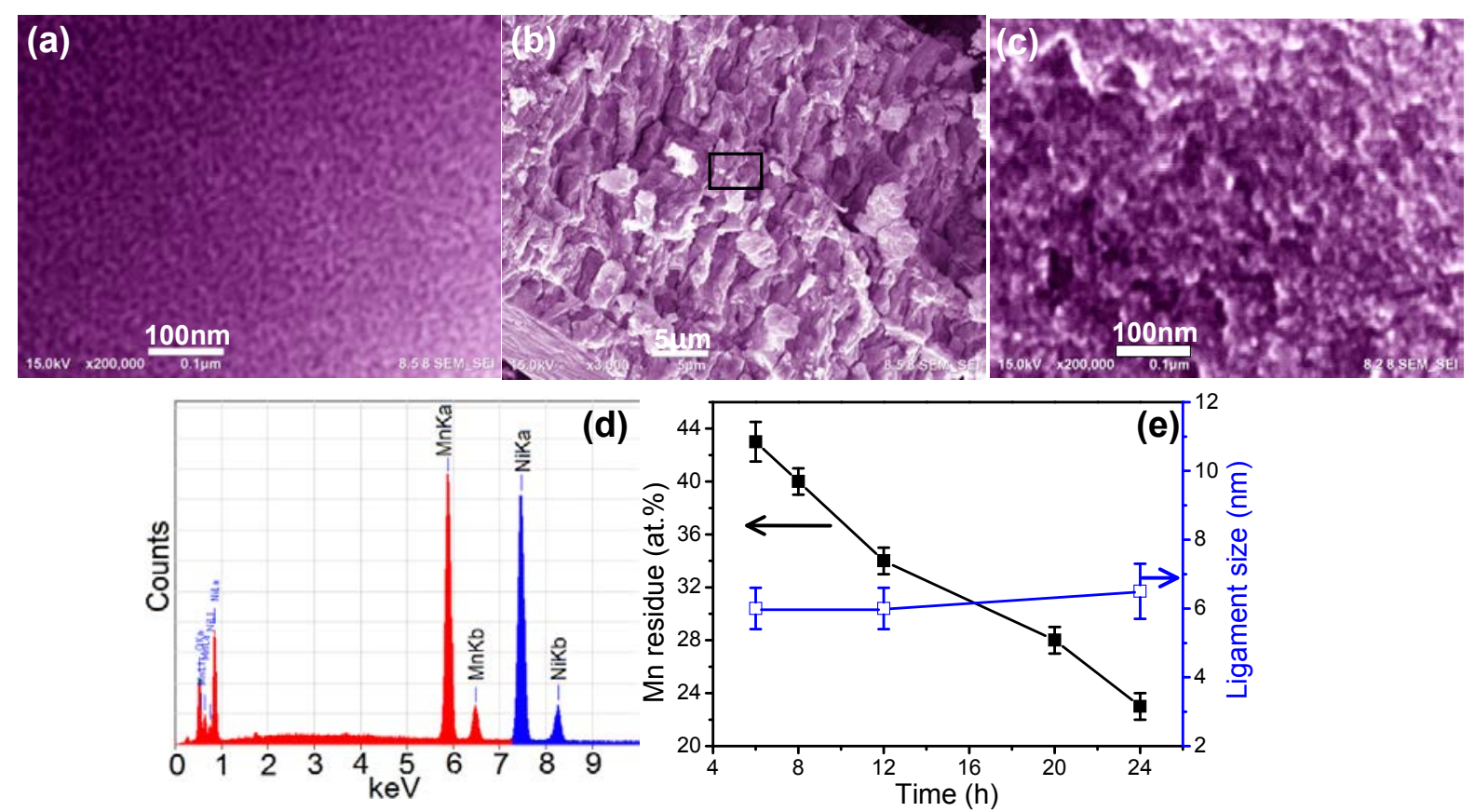
Fig. 3
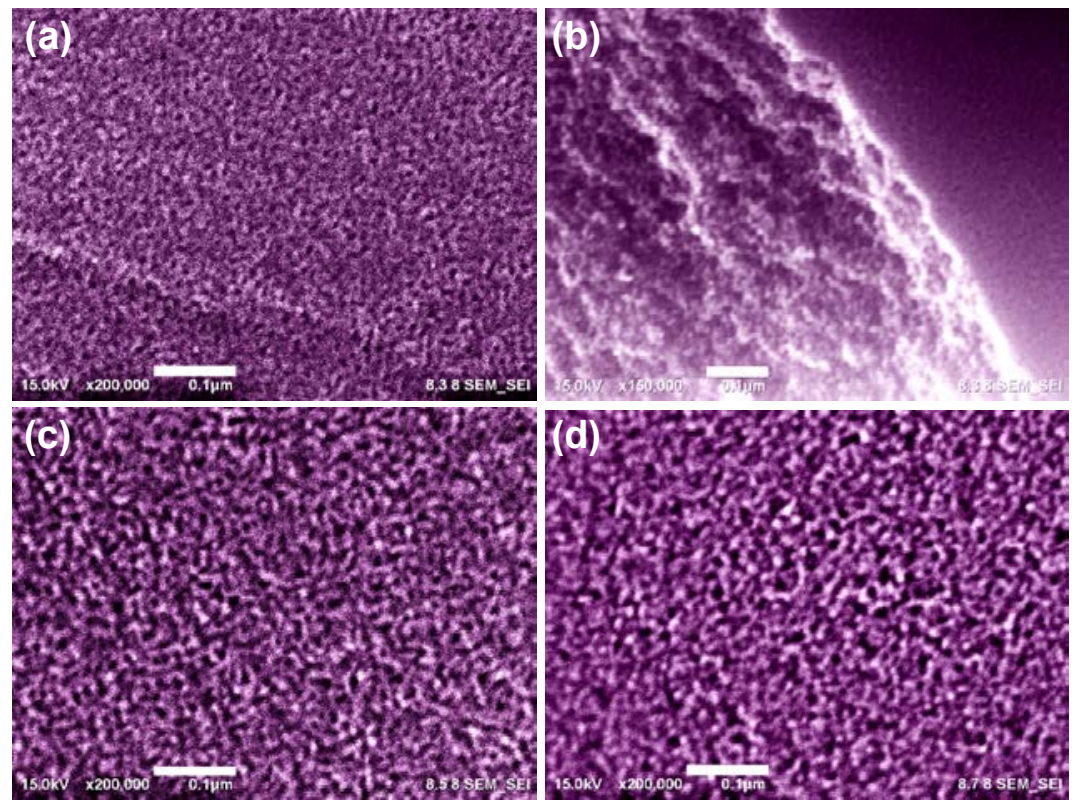
Fig. 4
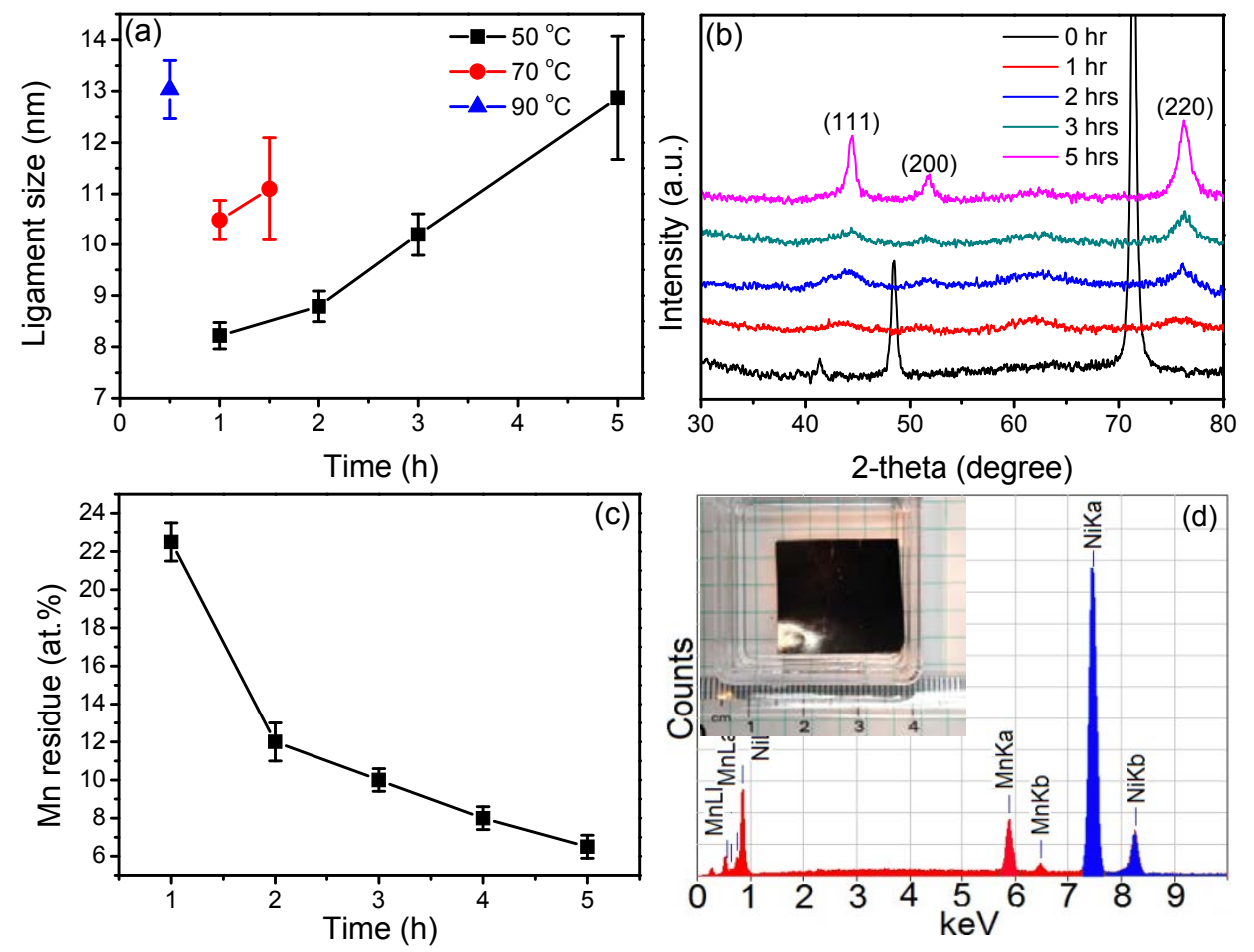
Fig. 5

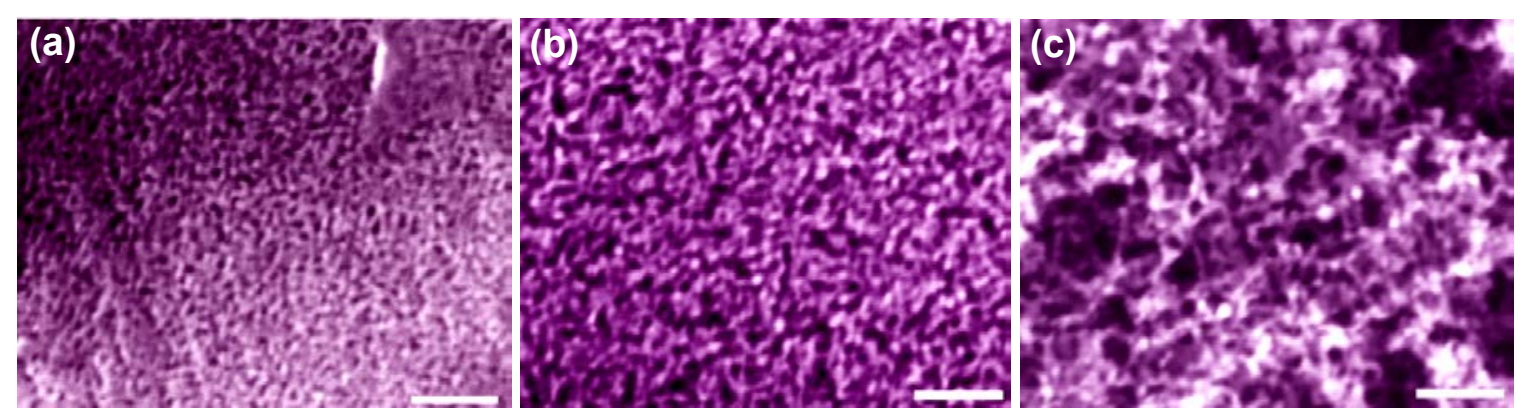


Fig. 6
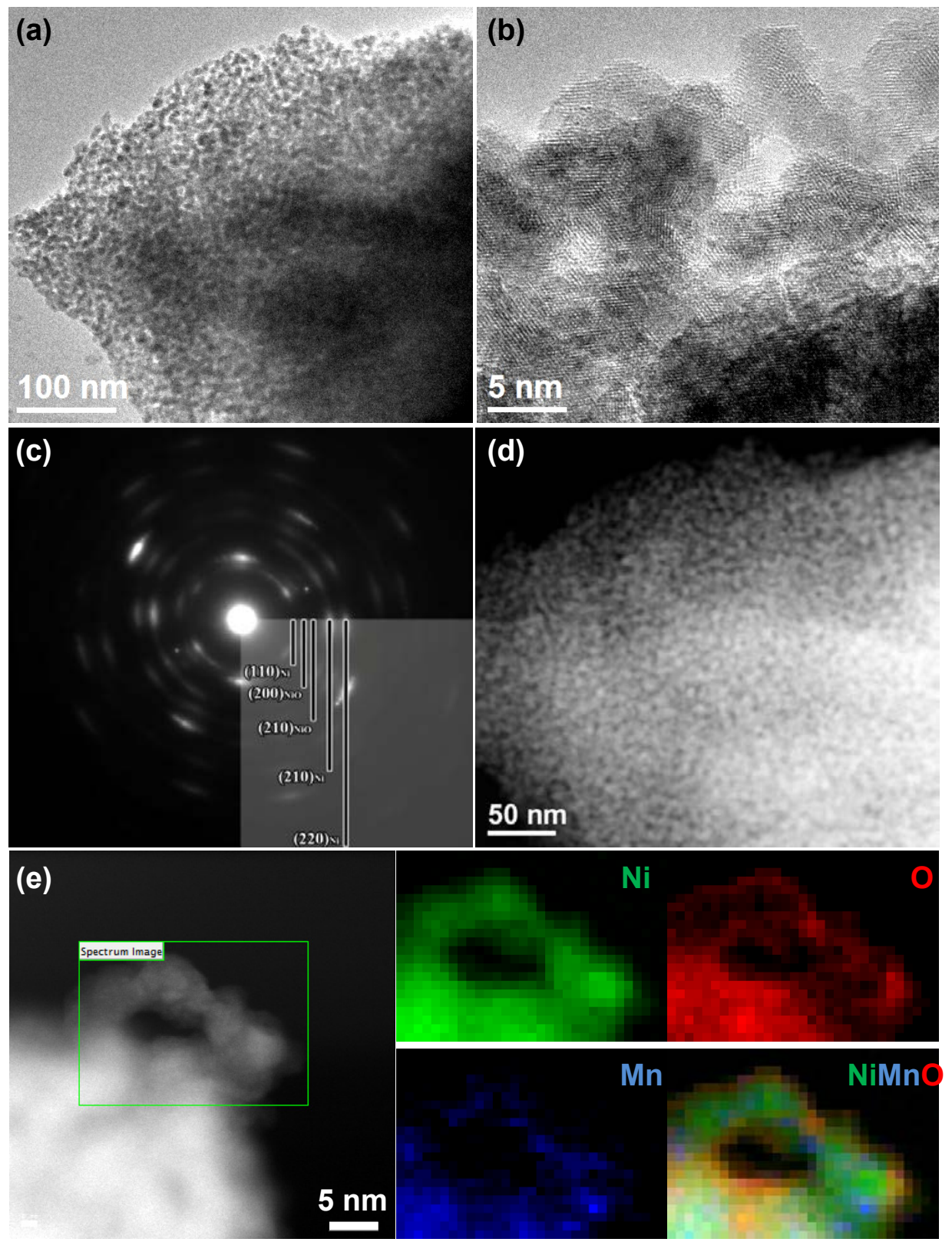
Fig. 7
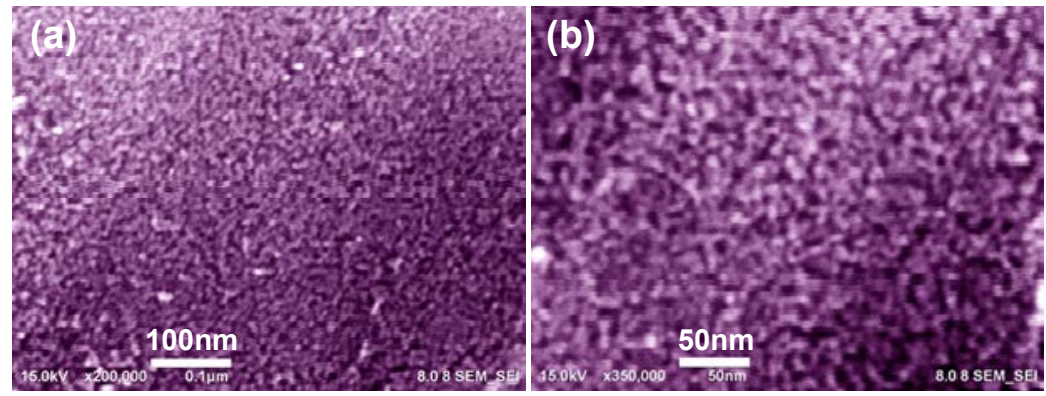

Fig. 8
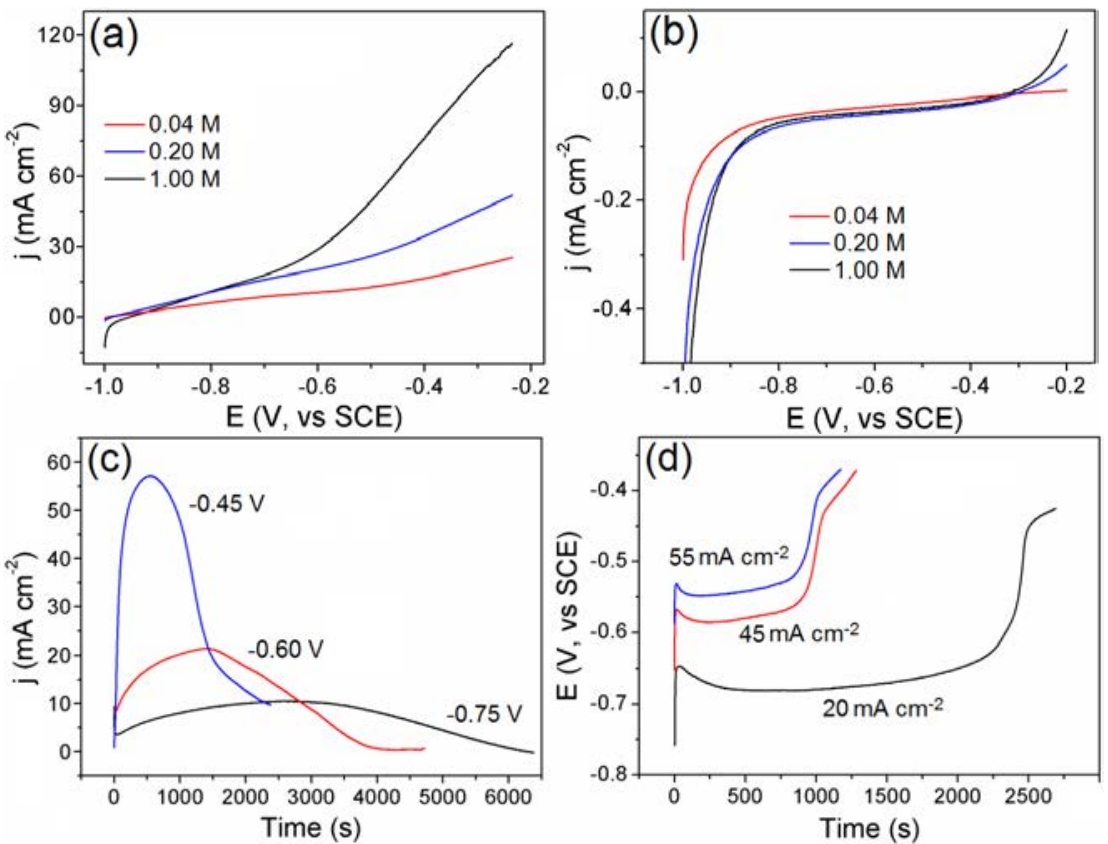
Fig. 9
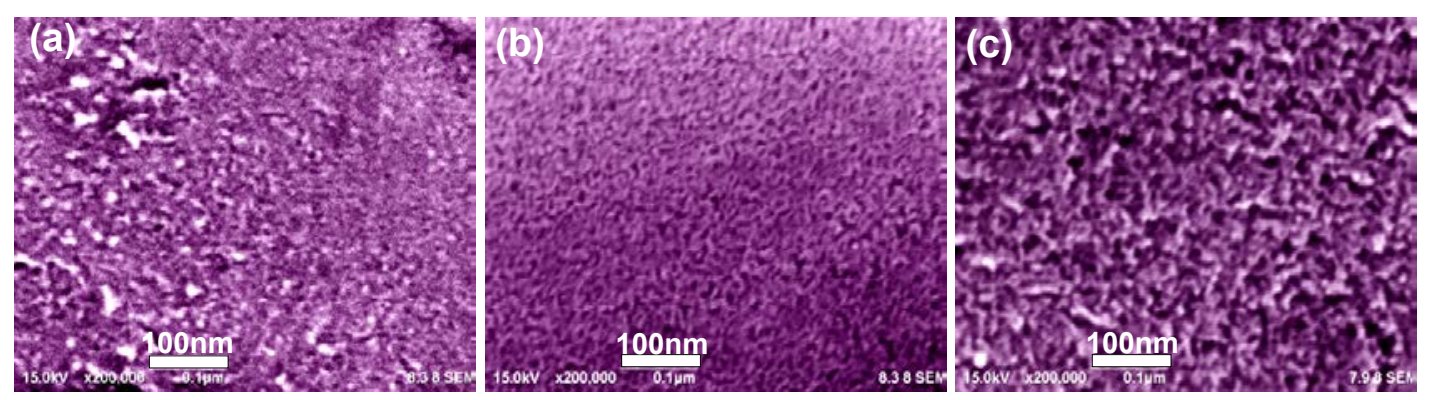
Fig. 10
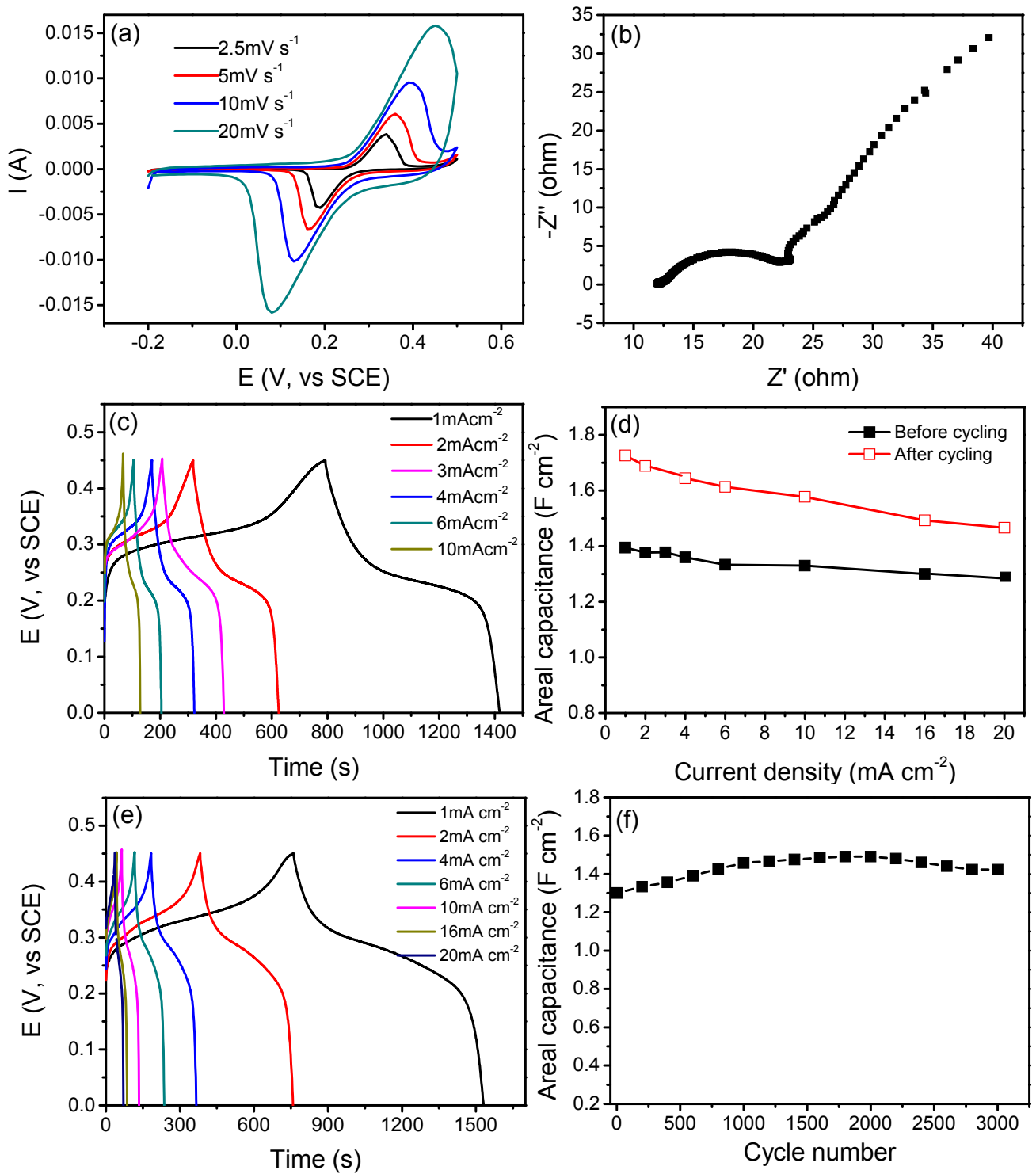